\title{
Factors Influencing Life Satisfaction of International Students in Mainland China
}

\author{
Qinxu Jiang ${ }^{1,2}$ (D) $\cdot$ Mantak Yuen ${ }^{1} \cdot$ Hugo Horta $^{3}$ \\ Published online: 4 August 2020 \\ (C) Springer Science+Business Media, LLC, part of Springer Nature 2020
}

\begin{abstract}
China is advancing in its bid to internationalize higher education, but little is known to date about the life satisfaction of overseas students in that country. Life satisfaction can be understood as the extent to which individuals' experiences in a host country help them achieve their personal goals and satisfy their expectations regarding acculturation. This paper examines past research, especially international literature, to provide an overview of factors that may influence the life satisfaction of international students in countries other than their own, and looks particularly at those matters that may also affect overseas students in China. Comparisons are made between variables identified in general and those in Asia, and specifically China. The findings have implications for policy-makers and university practitioners seeking to improve educational quality and counseling support services for international students.
\end{abstract}

Keywords China $\cdot$ Counseling services $\cdot$ International students $\cdot$ Life satisfaction

\section{Introduction}

In recent years, China has grown in prominence on the world stage. This includes its position as an emergent educational hub for international students (Wen and Hu 2019). Although many Chinese students undertake studies in North America, Western Europe and Oceania, China has also begun attracting increasing numbers of students from overseas. This phenomenon can be traced to the development of higher education in the country, with several Chinese universities now placing highly in world rankings, and to the country's growing economic prominence (Jiani 2017). Data

Qinxu Jiang

jiangqx@hku.hk

1 Center for Advancement and Inclusive and Special Education, Faculty of Education, The University of Hong Kong, Pokfulam Road, Hong Kong, China

2 Xuzhou Medical University, Yunlong District, Xuzhou, China

3 Social Contexts and Policies of Education, Faculty of Education, The University of Hong Kong, Pokfulam Road, Hong Kong SAR, China 
from the Chinese Ministry of Education (MOE) and the Ministry of Foreign Affairs (MFA) indicate that in 2018, there were 492,185 international students from 196 countries and regions studying in 1,004 higher education institutions within China's 31 provinces, autonomous regions, and provincial-level municipalities. This marks a six-fold increase from the total number of international students enrolled in China in 2008. ${ }^{1}$ Of course, it remains to be seen what effect the recent coronavirus outbreak, which originated in mainland China, will have on future trends.

Most international students in China come from elsewhere in Asia (59.95\%), with others coming from Africa (16.57\%), Europe (14.96\%), the Americas (7.26\%) and Oceania $(1.17 \%)$ (MOE 2019). Four of the top five countries of origin of these students are located within Asia; namely, South Korea $(50,600)$, Thailand $(28,608)$, Pakistan $(28,023)$, and India $(23,198)$, with the United States of America $(20,996)$ being the fifth (MOE 2019). It is noteworthy that only $52 \%$ of all international students in China are enrolled in extended degree programs (MOE 2019), with others participating mostly in language, cultural, and other social science short courses (Li 2016). This situation reflects that the Chinese internationalization of higher education is different from that of North America and Western Europe, where overseas students are mainly interested in degree programs, including for higher degrees (Yang 2014). In China, 33\% of international students in degree programs are in postgraduate programs (25,618 enrolled as doctoral students and 59,444 in Master's programs) (MOE 2019), while the remainder are enrolled in Bachelor's degree programs in various disciplinary fields, including medicine, engineering, the social sciences, and the humanities. ${ }^{2}$

China's emergence as one of the main countries in the world able to attract international students can be attributed to its affordable tuition fees, modest living expenses, economic growth, political stability, and accessible scholarships (Gbollie and Gong 2020; Jiani 2017). In relation to this last factor, 63,041 students from overseas, representing $13 \%$ of all international students in China, have received scholarships from the Chinese government (MOE 2019). Efforts at attracting overseas students have been driven by government policies designed to internationalize the country's higher education system, present China as a country wellintegrated within a globalized world, and by the desire to wield diplomacy and soft power perspectives (Mulvey 2019) - with soft power being the ability to attract and co-opt (rather than to coerce) based on "the attractiveness of a country's culture, political ideals, and policies" (Nye 2004, p.x). The expectation is that the values of the host country, as expressed through its culture, can influence international students' opinions and behaviors (Mulvey 2019).

In the research literature on this topic, several articles have focused on the internationalization of the Chinese higher education system and the increased inflow of international students (e.g., Zheng and Kapoor 2020). Less attention has been given to international students' experiences in Chinese universities and how these relate to their social and cultural adaptation and life satisfaction. This article contributes to the knowledge-base by identifying from relevant international and national literature the factors that may influence the life satisfaction of international students in mainland China. It then identifies similarities and differences between the experiences of international students elsewhere and those in China. Finally, it raises questions for future research and discusses the implications of this review for policy and practice.

This literature analysis is organized into the following sections. The first section considers the benefits of internationalization of higher education in China, the country's potential to

\footnotetext{
${ }^{1}$ International students in Hong Kong, Macau, and Taiwan are not included in the above data.

2 "Statistics of international students coming to China in the year 2018," an internal document of the Department of International Cooperation and Exchanges of the Ministry of Education.
} 
attract international students, and government initiatives around these matters. Following this section, the international literature on matters related to life satisfaction among overseas students in Western contexts and in other emerging Asian countries is reviewed. Similarities and differences are identified between observations in other countries and those in China. Factors that might predict the life satisfaction of international students in China are discussed. In this context, a general description of counseling services available in higher education institutions in China is provided, followed by suggestions for developing such services that address the specific needs of international students. In the final section, future possible research directions are proposed.

\section{Internationalization of Higher Education in China}

The ease of mobility of international students across borders has many advantages to both host countries and international students. The internationalization of higher education also yields appreciable economic benefits for host institutions, and this in turn can support research and increase resources and staffing (Horta 2009). A less tangible but no less valuable benefit is the positive interaction and cultural exchange that typically occurs between international students and domestic students (Ammigan 2019). A deeper understanding of different cultures can facilitate cooperation, tolerance and international peace (Gebregergis et al. 2019; Sam 2001; Taušová et al. 2019).

Residing and studying in a foreign country enables international students to have rewarding experiences that contribute to increased confidence and self-growth (Taušová et al. 2019), although the mobility of international students tends to be motivated more by financial goals than by deliberate cultural exchange (Feng and Horta 2020). An international student may acquire foreign language competency, multicultural experiences and enriched cultural literacy, thereby increasing their human capital of knowledge and skills (Wen and Hu 2019), as well as the scope of their employability (Nerlich et al. 2018). However, overseas students also face numerous adaptation challenges related to their social, cultural, and learning experiences, and not all their experiences are necessarily positive (Bamber 2014).

China entered the globalization movement of higher education at a later stage than the West, and although the country is increasingly attracting international students, it faces stiff competition from more established host countries such as the U.S., the U.K., Australia and New Zealand, as well as from neighboring countries like South Korea, Japan and Singapore. China's success in attracting overseas students can be attributed in major part to its affordable tuition fees and living expenses, which are lower than those in most Western countries (Dervin et al. 2018). China also has accessible scholarships, government grants and supportive policies for employment opportunities after graduation (Dervin et al. 2018). The opportunity to acquire Chinese language competence is also an attraction because of its value in the global business world (Ding 2016). Other factors that potential students take into account include China's political stability, its less strict admission policies, the economic boom and their own interest in Chinese culture and history (Jiani 2017; Liu et al. 2013; Wen and Hu 2019).

The internationalization of higher education and the recruitment of overseas students has been high on the Chinese government's agenda. The MOE formulated its Program for Study in China to strengthen educational exchange and cooperation between China and other countries. It aimed to develop study opportunities that would be accessible by international students. The plan set a target for China to become the Asian country with the largest number 
of foreign students by 2020 ; this number is anticipated to reach $500,000 .^{3}$ This was reinforced by the launching in 2013 of the One Belt One Road Initiative (OBOR, centered on a Silk Road Economic Belt and a Maritime Silk Road), which further opened China up to the rest of the world. Critical importance was attached to strengthening educational cooperation and exchange with several countries in Asia and in Central and Eastern Europe (Lu and Tian 2018).

The OBOR initiative is suggestive of how international education development can be seen as an exercise of soft power: it does not focus on revenue benefits (although it may generate a revenue stream), but rather is part of China's global strategy to influence attitudes overseas and increase awareness of China's culture and its economic and creative growth (Wen and $\mathrm{Hu}$ 2019; Yang 2015). In this context, it is relevant to note that international recruitment mostly targets students in developing countries. These students will likely become part of the governing elite in their countries and will potentially be more sensitive to Chinese viewpoints and interests after their stay in China, given their acquired knowledge of the Chinese language and China's society, culture, history and politics (Yang 2015, p. 25).

By April 2017, China had signed 45 cooperation agreements with countries along the "Belt and Road" and had signed mutual recognition agreements for academic degrees with 24 countries (China Youth Network 2017). Although these initiatives are important, future growth in the number of international students in China is bound to be more dependent on growing a reputation for the quality of the education and student experiences provided by Chinese universities. The fact that such students have to pay fees for their studies means they will always weigh whether they are getting value for money. Host nations must therefore be mindful of the need to meet their expectations (Karaman and Watson 2017).

\section{International Literature}

\section{Life Satisfaction of International Students}

Life satisfaction is defined as “a global assessment of a person's quality of life according to his [or her] chosen criteria" (Shin \& Johnson, 1978, cited in Diener et al. 1985, p. 71). It is also considered to be "a generic concept representing an individual's contentment with his or her life" - that is, the level of an individual's subjective appraisal as to whether his or her aspirations and goals have been achieved (Jacobsson \& Lexell, 2013, cited in Nilsson 2015, p. 87).

The life satisfaction of international students can be understood as the extent to which their experiences in the host country satisfy their expectations in terms of personal goals being realized and appropriate acculturation taking place. In other words, it is a subjective evaluation of a student's perceived level of satisfaction and adjustment to a new sociocultural environment.

\section{Acculturation}

Throughout the literature, international students' assessment of life satisfaction is closely linked to their acculturation experiences in the host country (Zhang and Goodson 2011). For example, they may encounter unexpected challenges and adjustment problems in an unfamiliar

\footnotetext{
$\overline{3}$ Recent data from the MOE (2019) show that by 2018, the number of international students in China had already exceeded 490,000 (China CCTV News 2018).
} 
culture, and may experience mental or psychological stress as a consequence. Acculturation is defined as "the dual process of cultural and psychological change that takes place as a result of contact between two or more cultural groups and their individual members" (Berry 2005, p. 698). International students and members of the host culture they connect with undergo acculturative changes through contact, adaptation and accommodation (Smith and Khawaja 2011; Zhang and Goodson 2011). Psychological adaptation refers to affective responses (sense of well-being, confidence and self-esteem) as well as physical well-being (Ward et al., 2001, cited in Smith \& Khawaja, 2011, p. 701). Sociocultural adaptation is "based on behavioral responses related to how effectively an individual links in to the new society" (Ward et al., 2001, cited in Smith \& Khawaja, 2011, p. 701). Having a clear understanding of international students' acculturation processes is helpful for understanding the factors that may predict their degree of life satisfaction in a new environment.

\section{Acculturation: Research in Western and Other Contexts}

A number of quantitative and qualitative studies have examined acculturation among international students. In their review of 94 studies on acculturation that had been published before 2011, Smith and Khawaja (2011) thoroughly investigated the acculturation experiences of international students, although almost all the studies they included were from Western countries. They identified five of the most common stressors facing such students: (i) language difficulties, (ii) educational factors, (iii) sociocultural differences, (iv) discrimination, and (v) practical problems, such as financial difficulties and accommodation or transportation issues. In Western host nations where English is the native language, a low level of English proficiency naturally affects international students' academic performance and social adjustment (Smith and Khawaja 2011). It can be deduced from their review that any similar setting in which a student has to cope with a language other than their first language is challenging. The mental strain brought about by unsatisfactory educational experiences or difficulties socializing and making friends can add to the stress.

A mismatch between a student's expectations regarding the ease or difficulty of academic courses and the reality of such contributes significantly to stress no matter the circumstances, but this stress can be compounded when it happens in a foreign country (Smith and Khawaja 2011). Access to counseling services can be important in helping students handle these stressors, but the problem can be exacerbated if the quality of the counseling and support services offered by the host educational institution is poor (Smith and Khawaja 2011). In such circumstances, acculturative stress can become debilitating and can significantly undermine a student's level of life satisfaction.

In their review, Smith and Khawaja (2011) identified sociocultural stressors associated with overseas students' attempts to build new social networks in their host country. They found that international students' individual characteristics, such as their personality or attachment style, affected their psychosocial adaptation (Smith and Khawaja 2011). A possible example of this finding is that Asian students from a collectivist culture may find it hard to accept Western social norms and attitudes that seem to conflict with their own. The same kinds of difficulties can occur in reverse, where a student from an individualized culture must cope in a collectivist society. This can be an obstacle to forming friendships, and if friendships are less accessible in the host community, loneliness may occur and be a negative predictor for life satisfaction (Salimi 2011; Yalçin 2011).

Discrimination against international students, sometimes evident through prejudice, verbal insults, physical assault or hostility, has also been recognized to be a significant acculturative 
stressor. International students were found to be more vulnerable to discrimination, in both covert and overt forms, on and off campus (Smith and Khawaja 2011). Discrimination not only discourages international students from making friends with local people but can also affect their mental health and wellbeing. In extreme cases, this can also cause a student to withdraw from study and return home. Other practical stressors that international students were found to be at risk of experiencing included financial, accommodation and transportation issues (Smith and Khawaja 2011). Naturally, however, data on the relevance and severity of these more practical factors may vary from country to country depending on conditions in different settings.

Zhang and Goodson (2011) reviewed 64 peer-reviewed American journal articles published between 1990 and 2009 to investigate predictors of international students' psychological adjustment to life in the U.S. Consistent with Smith and Khawaja's (2011) findings, factors such as general stress, social support, language proficiency, the characteristics of the origin country, social connectedness with locals, gender, self-efficacy, personality and length of stay in the host location were most frequently reported as influences on adjustment. It should be noted that the reviews by Smith and Khawaja and by Zhang and Goodson were published in 2011, so more recent data are needed, as the past nine years have seen rapid growth in international student mobility.

Mesidor and Sly (2016) contributed a more recent review (albeit drawing also only on U.S. sources) on the variables that contribute to international students' adjustment. Unsurprisingly, factors enumerated in their review overlapped with those identified by Smith and Khawaja (2011) and Zhang and Goodson (2011). They identified factors associated with academic issues, language barriers, sociocultural issues, financial problems, and lack of social support, but Mesidor and Sly (2016) also added more personal factors: emotional intelligence, resilience, locus of control, self-efficacy, coping styles and engagement in leisure activities.

An investigation of international students' satisfaction in life and its predictors was carried out by Sam (2001) at the University of Bergen, Norway, where universities widely use English as the medium of instruction. His paper provided a comprehensive review of earlier findings that focused on seven aspects that contribute to satisfaction in life: language proficiency, demographic characteristics, financial situations, academic standards, social activities and social relationships, and the clarity of information received prior to enrollment. In addition, in Sam's (2001) study, students from Europe and North America studying in Norway appeared to have a higher level of satisfaction than their counterparts from Asia and Africa. This may have been a reflection of students' English language proficiency and the tendency of Asian and African students on campus to experience more obvious discrimination and to have fewer friends. In addition, some of the latter students may have received inadequate information about courses prior to enrolment, leading to stress when faced with the reality of study demands. Sam (2001) recognized that, overall, the factors identified, together with difficult financial situations, seriously influenced the life satisfaction of the international students involved.

In the same study, there were also apparent differences between international students from developing countries and those from developed countries (Sam 2001). For example, interestingly, financial issues appeared to be of greater concern to students from developed countries than to those from developing countries. One possible reason for this difference, according to the researcher, may be that the latter group were typically recipients of financial support from their governments, while the others were not. These differences highlight the fact that influences on the life satisfaction of international students may vary considerably from one geographical, economic, or cultural setting to another. 


\section{Recent Research}

Studies since 2011 in both Western and non-Western contexts have tended to confirm the influence of all the factors previously identified. Language, educational experience, financial insecurity, discrimination, social integration, stress, living expenses, and accommodation continue to be common influential factors. For example, Ammigan (2019) pointed out that the main factors that predict international students' institutional satisfaction in the U.S., Australia, and the U.K. include social networking, work opportunities, suitable accommodation, and compatibility with local culture.

More recently, the following influences have gained attention in the literature, with seemingly more sophisticated variables being given attention: cultural distance/proximity, individual coping competence, campus support services, prior sojourn experience, and predeparture preparedness all seem to be particularly important for international students' adjustments (Alemu and Cordier 2017; Ammigan and Jones 2018; Hennings and Tanabe 2018; Kosheleva et al. 2015; Taušová et al. 2019).

\section{Cultural Proximity}

Taušová et al. (2019), in their Netherlands-based study of psychological adjustment among international students from 62 countries, investigated four factors of perceived cultural distance: (i) "subjectively perceived discrepancy between cultures in areas such as values, habits, norms, religion and leisure" (p. 13), (ii) perceived growth initiative, which refers to "striving to grow and achieve positive changes in personally important life domains" (p. 13), (iii) English and Dutch language proficiency, and (iv) length of residence. As with Norway, English rather than Dutch is the language most used both in academic and social spheres in the Netherlands.

Another study focused on Singapore (Nasirudeen et al. 2014), a multicultural society where the main language spoken is English. International students from neighboring Malaysia were found to have less stress and to experience less discrimination than students from China and Myanmar. This was mainly because the students from Malaysia had better English competence and shared similar cultural norms to the host nation. This finding reinforces the importance of having adequate proficiency in the language used in the higher education institution of any host country. Language proficiency is clearly a major influence on how quickly a foreign student is likely to become acculturated and to achieve a positive level of life satisfaction (Nasirudeen et al. 2014). In a large-scale study of 45,701 international students from 96 universities in Australia, the U.K. and the U.S. undertaken by Ammigan (2019), the English proficiency of the lecturers was found to be very important for overcoming students' stress associated with the demands of study.

In their study of international students in Korean universities, Alemu and Cordier (2017) found that international students from East Asian countries tended to be more satisfied with their experiences than other international students, largely because of their greater cultural proximity to the host nation. Based on this research, it can be deduced that foreign students who decide to study overseas are likely to encounter the most difficulties if they opt for a country with a different language and very different cultural norms from their home country.

\section{Individual Coping Competence}

Research studies have paid less attention to students' coping competence as a factor influencing how they adapt to a new environment. Smith and Khawaja (2011) acknowledged that most 
acculturation models recognize that an individual's coping mechanisms play a key role in how they adjust to and integrate into an unfamiliar host culture. A comparative study of determinants of life satisfaction among Chinese students in Finland and Russia indicated that those who were more able to cope with change and were open to new experiences tended to fit into the new culture faster, and with greater confidence and satisfaction (Svergun 2016). Saha and Karpinski (2016) found that international students who coped by using social media platforms such as Facebook, LinkedIn, Twitter, QQ, or Skype to seek social support from families and friends at home also tended to have higher levels of life satisfaction, which contributed to their overall academic performance.

It also appears that marital status can influence how easily a foreign student adjusts to a new country. For example, Bhandari (2012) found that married Nepalese participants who lived with their spouse in South Korea experienced less acculturative stress than did single students. Obviously, having such close support and shared experiences is helpful psychologically for international students, and it can also be claimed that couples might be more likely to become engaged with locals through social invitations extended to them as a couple.

It is not yet clear whether students' age, gender, and length of residence are linked to acculturative stress, so more research is merited in this area. For example, Sam (2001) found that female international students were less adaptive than males and that age and length of stay were positively correlated with students' adaptation abroad. Other studies have shown conflicting results in regard to the impact of these factors (Nasirudeen et al. 2014; Salimi 2011; Yalçin 2011).

\section{Campus Support Services}

The degree and quality of campus support services have been recognized in several studies to influence the life satisfaction of international students; these services can determine how well students cope while studying abroad. A quantitative study of the experiences of more than 45,000 international students from 96 institutions across Australia, the U.K. and the U.S. revealed that support from the International Office, services from the Financial Department, and assistance from tutoring services had a significant influence on international students' levels of satisfaction (Ammigan and Jones 2018). Similarly, in their study involving international students at an American university, Cho and $\mathrm{Yu}$ (2015) found a positive relationship between university support, a reduction of psychological stress, and an increase in life satisfaction.

The large-scale survey of 45,000 international students from 96 different institutions in Australia, the U.S. and the U.K. by Ammigan (2019) also revealed that international students' satisfaction with the level of support services (especially related to learning) influenced the decisions of prospective applicants. Effective advising (e.g., personal counseling and preparing potential students for their choice of overseas institution) was also found to be important for international students' satisfaction, engagement, persistence, retention, and academic performance (Bista 2015; Mamiseishvili 2012; Zhang 2018).

It is clear that counselors also play an integral role in supporting international students' academic success and well-being (Arthur 2017). Counseling can help international students address their immediate concerns, overcome problems, and thus strengthen their adjustment and decision-making abilities (Arthur 2017). Banjong's (2015) U.S. study found that amid the challenges of language, loneliness and financial difficulties, seeking help from a counseling center helped improve international students' academic success. 
One aspect of "fitting in" to a new educational environment is being able to use all available resources that are provided. Library services, for example, are a core resource used by international students upon arrival to transition into the new academic realm, with libraries being critical for engaging with academic content, which is central to the purpose of students being in the host nation. It should be standard procedure for host universities to help international students develop required scholastic skills, such as searching for information online and in print (Hughes et al. 2018; Toner 2019).

\section{Prior Experience and Pre-Departure Preparedness}

Students' prior sojourn experiences and pre-departure preparedness have been found to positively relate to adjustment and acculturation (Alemu and Cordier 2017; Gebregergis et al. 2019; Morrell et al. 2013; Park and Rubin 2012). International students who have traveled or worked in other foreign countries are likely to have more realistic expectations about the challenges and difficulties they might experience. Typically, they are better able to activate adaptation skills readily and experience less stress within a new environment than those with no previous international experience.

Pre-departure preparedness in terms of information provided by the host institution has also been found to influence how easily an international student adapts to a new study environment (Madden-Dent and Laden 2016). This pre-preparation information from host country settings typically includes not only important educational details about academic matters but also information about social life, accommodation, financial budgeting, and the availability of counseling and learning support services (Alemu and Cordier 2017). The provision of these resources by the educational institution conveys a sensitivity to the challenges that the incoming international students will be facing, and reassures students that such support will be available to them.

In summary, the above review of mainly Western research identifies several important factors that affect the life satisfaction of international students in general. The review also reveals that there may be differences in the relative importance of these factors according to the characteristics of the host countries and the students' countries of origin. Specific regional elements, therefore, have to be taken into account to avoid the risk of overgeneralizing the set of influences that determine international students' life satisfaction in any new study environment.

\section{Research on the Life Satisfaction of International Students in Mainland China}

Ding (2016) has pointed out that Western countries such as Germany, New Zealand, the U.K. and Australia have conducted surveys of international students to better understand their experiences of living and studying in the host country concerned. The results obtained have then been analyzed with the aim of improving educational services and the experiences of the students. In contrast, fewer studies have investigated the life satisfaction of international students in China, where these types of surveys have not yet been a major priority. Instead, the work of attracting students has been emphasized over the evaluation of course quality, support services, and levels of student satisfaction.

The available survey research of this type in China is four large-scale questionnaire surveys conducted in Shanghai (Ding 2010, 2016) and Beijing (Wen et al. 2013, 2018) about 
international students' experiences and levels of satisfaction. These studies identified several factors that were closely related to the life satisfaction of international students studying in mainland China. One limitation is that these investigations were carried out at universities in the two biggest and most metropolitan cities in China, where education and support services are believed to be more advanced than in other Chinese cities. In addition, the reality is that there are many more international students studying in China at educational institutions in what can be regarded as second-tier or third-tier cities. Therefore, to obtain more in-depth information about life satisfaction of international students, it is also necessary to review studies conducted in these smaller cities.

\section{Quality of Education}

In larger cities, the questionable quality of education seems to be the most frequently raised factor contributing to international students' dissatisfaction (Ding 2010, 2016; Sun et al. 2009; Tian and Lowe 2018; Wen et al. 2013, 2018). According to Ding (2010), only 32.3\% of 457 international students felt "satisfied" or "very satisfied" with the teaching quality they experienced, $25.0 \%$ felt "unsatisfied" or "very unsatisfied," and $42.8 \%$ perceived the teaching quality to be "average." The explanations given for these ratings were largely associated with instructors' teaching methods, which were perceived to be rigid spoon-feeding that required too much rote learning and lacked interactions between teachers and students. These perceptions often led to low class attendance rates among international students. It is possible that international students' levels of satisfaction could have been even lower if not for the fact that most international students in China originate from Asia, where similar types of learning (e.g., rote learning) are also prevalent. This potentially explains why the greater proportion of international students chose the option "average" in regard to teaching quality.

In a more recent study, Ding (2016) conducted a mixed-methods study involving a question-based survey and individual interviews with international students studying in universities in Shanghai. The survey found that $67.1 \%$ of 1,892 international students at 28 universities in Shanghai reported they were satisfied with studying and living in Shanghai, and $59.2 \%$ of them were willing to recommend studying in China to their social network. However, less than half of the students reported being satisfied with the education they received. Class sizes, outdated teaching materials, limited interaction with teachers in class, and unsatisfactory teaching methods were the most frequent targets of their complaints (Ding 2016). For instance, comments were made that teachers were more inclined to lecture and have students memorize material than to encourage self-motivated learning.

Wen et al. (2013) found that international students complained most about unreasonable curricula and obsolete teaching methods. For example, some courses were too researchoriented to be useful for practical work, or were arranged and structured only to comply with graduation requirements. Limited teacher-student interaction was another target of complaint, as were the lack of English used in teaching processes and the limited provision of technical support. For instance, most of the postgraduate seminars and tutorials were conducted in Chinese, barring international students with limited Chinese proficiency from participating.

In a more recent study, Wen et al. (2018) conducted a large-scale survey among 1,674 international students enrolled in universities in Beijing to investigate the quality of their educational experience. The results indicated that, overall, the international students were satisfied with their learning experience in China, with $83 \%$ of them feeling "very satisfied" or "satisfied." Yet the researchers also received reports from international students studying in 
English-medium programs that faculty members teaching the courses were not sufficiently proficient in English. Students opined that these teachers were not motivated to invest their time in improving their English because of the greater value given at their university to research rather than to teaching and learning (Wen et al. 2018).

Similarly, Tian and Lowe (2018) also found that international medical students thought their teachers had expertise in subject knowledge but were weak in English language proficiency, hindering them from giving clear explanations and answering questions. Their teaching style typically involved simply reading slides from overhead projectors. International students considered this ineffective, and this led to dissatisfaction and frustration (and even at times protest) among them.

Overall, regarding program quality, Yang (2018) suggested that Chinese institutions were often attracted to the prestige of "internationalization" without the level of commitment and resources needed to strengthen their programs.

\section{Campus Support Services}

The second domain about which international students in China tended to report less satisfaction was campus support services. To begin with, international students noted a scarcity of adequate and transparent information (Ding 2010; Tian and Lowe 2018). They complained, for instance, that the English websites of institutions often failed to reasonably meet students' information needs, and that administrative services sometimes failed to promptly inform them of changes to arrangements, preventing them from making adequate preparations. Similarly, Tian and Lowe (2018) found that international students thought that information on university websites was insufficiently clear. Some students also reported that their local agencies at home had provided them with inaccurate information before they reached their host university in Xi'an.

Apart from perceived problems with information and communication, other support services were also perceived to be inadequate for international students' actual needs (Ding 2016; Tian and Lowe 2018; Wen et al. 2013; Zhou et al. 2018). In one study, more than $30 \%$ of international students reported that they did not receive assistance with airport pick-ups, opening a bank account, or finding an apartment to rent (Ding 2016). Many international students reported feeling disappointed by the lack of activities on campus because their desire to interact socially with Chinese students could not be fulfilled (Tian and Lowe 2018). In terms of guidance for seeking employment, there was a lack of information specifically for international students who desired to work in China after graduation (Wen et al. 2013). In one study, most students found that the career planning help from the campus Employment Guidance Office was not open to international students (Wen et al. 2013).

Zhou et al. (2018) undertook a focused investigation on the extension of university library services to meet the needs of international students in China. In-depth interviews with 23 international students at a Wuhan university revealed their dissatisfaction with the library services. Five recommendations emerged from the interviews. First, it was thought to be essential to build a "bilingual library environment" with regard to library signage, management regulations, rules and restrictions, and website design. Next, it was recommended that high priority be given to increasing librarians' English skills and cultural sensitivity. Third, it was recommended that collaborative relationships be established between the library and the School of International Education. Fourth, it was considered necessary to improve library space allocation. Finally, there was seen a need to develop diversified library collections. From 
this study, it can be inferred that tailoring library services to international students in mainland China still has a long way to go.

Accommodation appears to be another salient issue among international students studying in China (Tian and Lowe 2018; Wen et al. 2013). In Beijing, survey results indicated a relatively high percentage (77\%) of international students feeling "satisfied" with or "very satisfied" with accommodation, but this figure was below an international standard of $86 \%$ (Wen et al. 2013). International students complained about a wide range of problems, such as slow Internet speed, a hot water supply shortage, old dormitory facilities, limited visitor time, unprofessional attitudes of dormitory staff, a shortage of single rooms, fees for Internet and electricity use, and the separation of international students' accommodation from that of local students (Tian and Lowe 2018; Wen et al. 2013).

International students also expressed dismay with the quality and efficiency of administrators, with some administrators appearing to them to be unfriendly and unhelpful. There also seemed to be a lack of collaboration between departments, with international students finding it difficult to find help solving their problems, which often cut across several areas of responsibility (Ding 2010).

\section{Limited Social Integration with Chinese Students}

International students in China usually have separate coursework and accommodation from Chinese peers. In the research, this separation was found to hinder international students from connecting with and getting to know Chinese students, thus limiting their studies and quality of life (Ding 2016; Tian and Lowe 2018; Wen et al. 2013). Interestingly, Chinese students were at times perceived by international students to be unfriendly (Ding 2016). This observation might be attributed to the degree to which Chinese students are typically preoccupied with their own studies and their lack of motivation for befriending foreigners.

\section{Financial Stressors}

Ding (2010) found that international students often wished to do part-time jobs to support themselves because most were relying on parents or relatives for their expenses. Even students on scholarship sometimes found their funding insufficient to cover both study and living expenses. Sun et al. (2009) noted that some international students grappled with tuition and accommodation fees and tended to experience more anxiety and insecurity when a part-time work permit could not be obtained, with this often being restricted by Chinese law. Wen et al. (2013) found that international students were more satisfied with tuition fees, living expenses and scholarships in Beijing because the municipal government there had invested more funding to support international student education.

\section{Acculturation}

Sun et al. (2009) surveyed 450 international students from 13 universities in the cities of Kunming, Beijing, Guangzhou and Shanghai on the three dimensions of (i) social adaptation, (ii) psychological adaptation, and (iii) cultural adaptation. The findings indicated that the students' social adaptation was satisfactory on the whole, but they at times reported unsatisfactory encounters with, and poor services from, people from government departments (Sun 
et al. 2009). They felt most comfortable making friends and going shopping, and they expressed satisfaction with their accommodation.

The study also found that the majority of the students had positive experiences of psychological adaptation, but there were some students who felt lonely, sad and disappointed. More women than men reported negative emotional experiences. The findings also showed that international students who lacked social support had the lowest levels of adaptability, while those who experienced social support, mainly from co-nationals and Chinese people, had the best levels of adaptability (Sun et al. 2009).

Regarding cultural adaptation, Sun et al. (2009) noted that international students often found some Chinese traditions and rituals hard to understand. According to the researchers, the adaptability of European and American students studying abroad was higher than that of Asian students. They attributed four possible reasons for this: (i) foreign students' intrinsic motivation to study in China vs. the pressure of Asian parents' expectations, (ii) more adequate psychological preparedness of European and American students for adaptation vs. inadequate preparedness among Asians, (iii) individualistic cultures in the West vs. collectivist cultures, and (iv) strong financial background vs. weaker financial status.

It should be noted that the study by Sun et al. was undertaken a decade ago in 2009, and it provided a broad understanding of international students' acculturation and satisfaction with life and learning in China at that time. It is hoped that the situations they described have improved since then, as indications are that China has progressed considerably in terms of public services and the quality of higher education. However, it is important for topical research to be undertaken to determine whether such changes are reflected in the experiences and perceptions of international students studying in mainland China at present.

Tan (2013) addressed the adaptability of foreign students to studying in China and suggested that it was natural for international students who had lived in China for longer periods to be better adapted than new arrivals. The latter faced difficulties with social integration, a lack of orientation or counseling services, and communication with Chinese staff and classmates; with these factors being confirmed as having an impact on acculturation (Li 2007; Tan 2013).

Gebregergis et al. (2019) addressed the issue of acculturation in their study. They explored the correlation of the three variables of prior travel experience, age, and cultural intelligence (understanding a culture that is not your own and the ability to relate effectively across cultures). They then related these to acculturative stress and depression among international students studying in Wuhan. Their findings showed that students with prior international experience had lower acculturative stress and were prone to less depression than those without such prior travel experience. Age had a negative correlation with acculturative stress and depression in the study, with younger students demonstrating more openness to new experiences and more flexibility in their coping strategies. Cultural intelligence was found to be negatively correlated with acculturative stress and depression. International students with more multicultural awareness or experience were less prone to acculturative stress and depression.

\section{Language Barrier}

Findings from an empirical study by Li et al. (2015) revealed that students from China's neighboring Asian countries found it less difficult to integrate into Chinese society than international students with more cultural distance from China. Nonetheless, the Chinese language proved to be a major barrier for them, hindering them from communicating easily 
with Chinese people. For example, even in Beijing, a cosmopolitan city where English is more commonly used, international students who lacked either Chinese or English language proficiency tended to experience more communication obstacles (Wen et al. 2018). It was not surprising to find that international students who had good proficiency in a local dialect spoken in the city where they studied, or who spoke Chinese more in daily life, were more likely to have adapted well and to express higher levels of satisfaction (Sun et al. 2009).

\section{Perceived Discrimination}

Tian and Lowe (2018) found that the perceived wealth of international students' countries of origin seemed to influence administrators' attitudes toward the students. It was also reported that black students were more vulnerable to racist attitudes, although this was not widespread (Tian and Lowe 2018). There is a need to research more deeply the issues of discrimination and racism that seem to occur (although they are often hidden) when international students of different backgrounds interact with peers and staff in host educational institutions. Because of the deeply personal impact of such attitudes and behaviors, such experiences inevitably have a major effect on life satisfaction and adaptation.

International students committed to a religion that they openly practiced tended to encounter more difficulties making friends and maintaining religious activities, and this was a potential source of considerable stress (Bin et al. 2014). For example, Muslim international students reported that they were not allowed to pray in public, but only in their dormitory corridors (Tian and Lowe 2018). Furthermore, Muslim and Hindu students who had food restrictions found it difficult to eat with Chinese students, and those who could not find food that tasted familiar expressed higher levels of homesickness (Li et al. 2015).

\section{Similarities and Differences}

This review of the literature on international students attending universities in mainland China seems to suggest that factors contributing to life satisfaction and adjustment are similar to those found in other countries. These factors include language barriers, issues with acculturation, financial hardship, cultural proximity/distance, perceived discrimination, campus support services, age, gender, marital status, length of residence, prior sojourn experience, predeparture preparedness, and individual coping skills. Yet studying in China seems to pose particular challenges in the form of language barriers and the limited availability of campus support services. The language barrier is especially significant because international students have to speak Chinese for everyday tasks, such as shopping, renting an apartment, seeing a doctor, traveling, using banking services, consuming entertainment, and eating in a restaurant, apart from tasks within the crucial educational context. Those who are unable to speak Chinese adequately tend to be constantly challenged and typically struggle more with life satisfaction and adaptation.

Ding (2016) and Wen et al. (2013) have pointed out that the overall satisfaction level of international students in China is lower than that recorded in other host countries, especially compared with countries like the U.S., the U.K., Australia and New Zealand. There seem to be four possible reasons for this situation: (i) educational institutions in other settings may be more revenue-driven and thus may attach more importance to maintaining international students' satisfaction; (ii) the universities in these other host countries may have developed better styles of teaching; (iii) the settings mentioned use English as the mode of instruction; and (iv) the 
settings mentioned have better curricula and well-designed course materials. Their years of experience as providers of courses to an international market have taught them the importance of support service systems for student applications, student orientations, and counseling services (Smith \& Khawaja, 2011). In comparison, China seems at this stage to fall short in these aspects, and Chinese universities seem to rely too heavily on outside agencies to recruit, inform, and prepare potential students. It seems evident from the studies reviewed here that Chinese institutions may be unaware of the need to improve their services, are resistant to change, or are in the process of adapting but are still in the early stages of doing so.

\section{Conclusion}

China has created a number of favorable policies designed to attract international students, and Chinese universities have made considerable efforts to increase enrollments, but it is important to ensure that current practices and offerings are valued by international students and are sustainable in the long term. China's eagerness to build a reputation as a world-class provider of university education is undermined by international students' perceptions of the quality of experience currently provided. Too little attention has been given to researching and addressing the needs of foreign students. China has not actively evaluated its higher education practices, so improvements have been slow to eventuate. With the global advancement of higher education, competition for enticing students at home and abroad will become even more fierce. Because hosting international students is crucial to China's soft power strategy, it is important for the Chinese government and higher education institutions to more successfully meet the expectations of overseas students, and to ensure that their life satisfaction is strengthened rather than undermined by their experiences in China.

\section{Implications for Policy and Practice}

The life satisfaction of international students studying in China is clearly influenced by multiple factors. To increase the satisfaction of international students, efforts should be made to improve four main domains: (i) the quality of the courses offered, (ii) the greater use of English language to communicate at all levels, (iii) support services development, and (iv) counseling services.

First and foremost is the need to improve the quality of education provided in Chinese universities, particularly in terms of teaching style, curriculum content, and study materials. Research has confirmed that to ensure ongoing recruitment and retention, high-quality education must be provided that meets the needs and expectations of international students (Alemu and Cordier 2017; Ammigan and Jones 2018; Ding 2016; Jiani 2017; Tian and Lowe 2018; Wen and $\mathrm{Hu}$ 2019). It is imperative that regular surveys of international students' evaluation of teaching and support services be conducted, and any deficiencies detected should be addressed at both government and institution levels.

Second, it is clearly essential that lecturers and teaching assistants in China receive adequate training in English proficiency and oral presentation skills. They need to observe examples of interactive teaching methods that engage students more effectively and establish good teacher-student rapport. This can be achieved through international teacher-exchange programs and video viewings of good practice. The lecturers also need to acquire better cultural knowledge of international students' backgrounds and their 
expectations. Course textbooks and materials should be updated regularly, and full use should be made of e-learning and related technology.

Thirdly, support services should be developed and extended to meet international students' needs. Areas most in need of strengthening include better website pre-enrollment information, better orientation programs for new students, ongoing counseling services, and employment guidance. International students are now used to accessing information and services online, so Chinese universities should make full use of the Internet to provide fast and convenient communication channels between lecturers and students and between students themselves. It is also recommended that policies be formulated and funding provided to improve accommodation and strengthen logistical services appropriate for international students.

International students' social interactions with Chinese students can be enhanced in all Chinese universities through activities such as cultural exchange programs and Chinese language courses. Improved Chinese language skills help overseas students function more effectively in the local community and within the institution. Developing friendships with Chinese students and fellow international peers is important for international students to reduce their loneliness and help them feel more engaged (Hendrickson et al. 2011; Smith and Khawaja 2011).

Fourthly, strengthening counseling services would greatly assist international students (Yalçin 2011). Counselors can help to improve students' level of optimism and motivation through professional work and the establishment of a social support network. Counseling support services are a basic necessity in Chinese universities, but currently they are very inadequate compared to services in Western settings. At present, student counseling services at China's higher education institutions are mostly limited to employment guidance and psychological counseling for local students (Li 2010). However, Chinese colleges and universities have begun to attach greater importance to psychological counseling for all students. Most of these institutions are establishing centers equipped with facilities (both rooms and resources) for individual counseling and group sessions. Counselors are allocated a certain number of students each year, and telephone counseling, online counseling, peer counseling, and other methods are being used (Su and Wang 2015). To meet the needs of students, some colleges have administered vocational ability tests to assist with career planning and provided psychological counseling for job candidates. Each institution has specific counseling services tailored to their student population. Overall, multiple counseling methods are being developed, and they should take full account of students' feedback, as has been made evident in this paper ( $\mathrm{Su}$ and Wang 2015).

Issues facing counseling services in Chinese universities merit particular attention. First, Chinese students tend to have misconceptions about counseling, associating it with mental illness or psychological abnormalities. For this reason, they fear that they may be stigmatized by their classmates or teachers if they seek counseling ( $\mathrm{Su}$ and Wang 2015). Their reluctance may also be fed by the collectivist cultural influence that constrains help seeking (Raunic and Xenos 2008). Another possible explanation for students' reluctance is that counseling services at this point seem to fall short of achieving their aims on campus. Students doubt whether counselors are able to communicate with them and really understand their worries or problems (Sun 2019). Thereupon, eliminating students' misconceptions and mistrust of counseling may be an ice-breaking step towards addressing their needs.

Secondly, there is a shortage of professional counselors with appropriate skills, training and experience, with this causing counseling-type duties to fall upon other staff members. Often, these personnel are student affairs professionals who take general care of a large number of students for such matters as studies, extra-curricular activities, dormitory checks, management 
matters, and discipline. The shortage of professional counselors, if not addressed, may add more work burden to student affair professionals and deter from achieving the objective of professional counseling in a real sense.

Third, the emergence of counseling services for international students has been slow at some universities in China, and services for career planning or employment guidance for such students are barely visible. The counseling and consulting services that are available tend to focus on providing the general student population with socialist political guidance, life values, and education about vocational ideals, rather than on providing guidance to individual students for their problems and stress management needs (Li 2010). Additionally, students perceive the counseling environment to be insufficiently private, which greatly affects their levels of openness in psychological counseling communication. English language proficiency is also a challenge for counselors, and speaking only in Chinese with foreign students who have limited Chinese language skills can hardly achieve desired outcomes (Xu et al. 2016).

The most important goal for the immediate future is for Chinese higher education institutions to acknowledge international students' counseling needs. Resources should be invested to build professional counselor teams to serve this increasingly large group of students if Chinese universities and colleges are to continue to attract overseas enrolments. Multicultural awareness training and language training are essential for all lecturers and counselors because international students comprise a heterogeneous group with unique cultures, religions, traditions, values, expectations, and ways of thinking (Arthur 2017). Intercultural competencies for counselors could help them better understand students' perspectives when they are involved in cross-cultural counseling (Pattison and Robson 2013).

More counseling services are expected to be provided in future, including academic advising, language tutoring, career planning, and employment guidance. Modes of online and offline counseling can be combined flexibly and innovatively (Sun 2019). This should help to enhance students' quality of life and levels of satisfaction. For instance, during the current situation of the COVID-19 pandemic, in which face-to-face counseling is not feasible, online counseling should be offered to mitigate international students' anxiety and distress.

\section{Future Research}

Although knowledge of the influences that affect international students studying abroad is significant, several areas would benefit from further empirical research in the Chinese context. ${ }^{4}$ First, it would be valuable to explore precisely what matters most to international students when they study in the Chinese context and which services should be provided or improvedfor example, academic and career counseling, psychological counseling, and career guidance. Second, studies should investigate how international students' academic success is affected by the very formal teaching methods traditionally used in China. Does this approach hinder them from achieving their goals and expectations? A third important issue to investigate is how individual students differ in the way they cope with the challenges they face. Such information would help those who counsel and support international students. It could lead to the

\footnotetext{
${ }^{4}$ Yang (2018) points out that research on international students in China remains relatively sparse. In terms of research gaps, most research methods applied have involved correlation analysis and regression analysis; other designs are needed to determine causal relations between variables. There is also a need for more longitudinal and qualitative studies to examine the psychological and sociocultural acculturation of international students studying in mainland China.
} 
development of powerful ways of assisting students in developing coping strategies and resilience. In addition, in the context of the COVID-19 global pandemic, it is important to study the impact of the crisis on international students' desire to study abroad, the learning progress of those affected by the pandemic, and their psychological stress and corresponding coping strategies.

Acknowledgements The paper is based on Qinxu Jiang's doctoral research under the supervision of Hugo Horta and Mantak Yuen at the University of Hong Kong Faculty of Education.

\section{Compliance with Ethical Standards}

Conflict of Interest The authors declared that they have no conflict of interest.

\section{References}

Alemu, A. M., \& Cordier, J. (2017). Factors influencing international student satisfaction in Korean universities. International Journal of Educational Development, 57, 54-64. https://doi.org/10.1016/j. ijedudev.2017.08.006.

Ammigan, R. (2019). Institutional satisfaction and recommendation: What really matters to international students? Journal of International Students, 9(1), 262-281. https://doi.org/10.32674/jis.v9i1.260.

Ammigan, R., \& Jones, E. (2018). Improving the student experience: Learning from a comparative study of international student satisfaction. Journal of Studies in International Education, 22(4), 283-301. https://doi. org/10.1177/1028315318773137.

Arthur, N. (2017). Supporting international students through strengthening their social resources. Studies in Higher Education: The International Student Experience: Voices and Perspectives, 42(5), 887-894. https://doi.org/10.1080/03075079.2017.1293876.

Bamber, M. (2014). What motivates Chinese women to study in the UK and how do they perceive their experience? Higher Education, 68(1), 47-68. https://doi.org/10.1007/s10734-013-9679-8.

Banjong, D. N. (2015). International students' enhanced academic performance: Effects of campus resources. Journal of International Students, 5(2), 132-142.

Berry, J. W. (2005). Acculturation: Living successfully in two cultures. International Journal of Intercultural Relations, 29(6), 697-712. https://doi.org/10.1016/j.ijintrel.2005.07.013.

Bhandari, P. (2012). Stress and health related quality of life of Nepalese students studying in South Korea: A cross sectional study. Health and Quality of Life Outcomes, 10(1), 26-26. https://doi.org/10.1186/14777525-10-26.

Bin, Y., Xinguang, C., Shiyue, L., Yang, L., Angela, J. J.-T., \& Hong, Y. (2014). Acculturative stress and influential factors among international students in China: A structural dynamic perspective. PLoS One, 9(4), e96322. https://doi.org/10.1371/journal.pone.0096322.

Bista, K. (2015). Roles of international student advisors: Literature and practice in American higher education. International Education, 44(2), 87-101,109.

China CCTV News. (2018). Ministry of Education: Over 490,000 international students came to China in 2018, "Study in China" becoming a brand. https://baijiahao.baidu.com/s?id=1636684200569997119\&wfr= spider\&for=pc

China Youth Network. (2017). Ministry of Education: In the past five years, more than 350,000 people from China have gone to study in countries along the "Belt and Road". http://news.youth.cn/jsxw/201705 /t20170512 9739269.htm

Cho, J., \& Yu, H. (2015). Roles of university support for international students in the United States: Analysis of a systematic model of university identification, university support, and psychological well-being. Journal of Studies in International Education, 19(1), 11. https://doi.org/10.1177/1028315314533606.

Dervin, F., Härkönen, A., \& Du, X. (2018). International students in China: A dream come true? In F. Dervin, X. Du, \& A. Härkönen (Eds.), International students in China: Education, student life and intercultural encounters (pp. 1-14). Cham: Springer International Publishing.

Diener, E., Emmons, R. A., Larsen, R. J., \& Griffin, S. (1985). The satisfaction with life scale. Journal of Personality Assessment, 49(1), 71-75. https://doi.org/10.1207/s15327752jpa4901_13. 
Ding, X. (2010). What kind of education do international students in China need: On the basis of data from four universities in Shanghai. Journal of Higher Education (6), 38-43.

Ding, X. (2016). Exploring the experiences of international students in China. Journal of Studies in International Education, 20(4), 319-338. https://doi.org/10.1177/1028315316647164.

Feng, S., \& Horta, H. (2020). Brokers of international student mobility: Role and processes of education agents in China. European Journal of Education. Under Review.

Gbollie, C., \& Gong, S. (2020). Emerging destination mobility: Exploring African and Asian international students' push-pull factors and motivations to study in China. International Journal of Educational Management, 34(1), 18-34. https://doi.org/10.1108/IJEM-02-2019-0041.

Gebregergis, W., Huang, F., \& Hong, J. (2019). Cultural intelligence, age and prior travel experience as predictors of acculturative stress and depression among international students studying in China. Journal of International Students, 9(2), 511-534. https://doi.org/10.32674/jis.v9i2.964.

Hendrickson, B., Rosen, D., \& Aune, R. K. (2011). An analysis of friendship networks, social connectedness, homesickness, and satisfaction levels of international students. International Journal of Intercultural Relations, 35(3), 281-295. https://doi.org/10.1016/j.ijintrel.2010.08.001.

Hennings, M., \& Tanabe, S. (2018). Study abroad objectives and satisfaction of international students in Japan. Journal of International Students, 8(4), 1914-1925. https://doi.org/10.5281/zenodo.1472920.

Horta, H. (2009). Global and national prominent universities: Internationalization, competitiveness and the role of the state. Higher Education, 58(3), 387-405.

Hughes, H., Cooper, L., Flierl, M., Somerville, M. M., \& Chaudhary, N. (2018). The role of the university library in supporting international student transition: Insights from an Australian-American case study. The Journal of Academic Librarianship, 44(5), 582-594. https://doi.org/10.1016/j.acalib.2018.06.003.

Jiani, M. A. (2017). Why and how international students choose mainland China as a higher education study abroad destination. Higher Education, 74(4), 563-579. https://doi.org/10.1007/s10734-016-0066-0.

Karaman, M. A., \& Watson, J. C. (2017). Examining associations among achievement motivation, locus of control, academic stress, and life satisfaction: A comparison of U.S. and international undergraduate students. Personality and Individual Differences, 111, 106-110. https://doi.org/10.1016/j.paid.2017.02.006.

Kosheleva, E. Y., Amarnor, A. J., \& Chernobilsky, E. (2015). Stress factors among international and domestic students in Russia. Procedia - Social and Behavioral Sciences, 200(C), 460-466. https://doi.org/10.1016/j. sbspro.2015.08.096.

Li, D. (2007). Research and countermeasure on intercultural cultural psychology adaptation of foreign students in China. Journal of Yunnan Normal University, 39(5), 49-51. https://doi.org/10.3969/j.issn.10005110.2007.05.009.

Li, S. (2016). Educational research and new exploration of non-degree students studying in China. Asia-Pacific education, 294. Doi:https://doi.org/10.16550/j.cnki.2095-9214.2016.28.240.

Li, Y. (2010). A comparative study of student guidance and consulting services in Chinese and American universities. China Adult Education, 000(21), 144-146.

Li, Z., Liu, X., Wen, X., \& Zhang, W. (2015). A study on the intercultural adaptability of foreign students: Taking a university survey as an example. Education Teaching Forum (51), 62-63.

Liu, Y., Wang, H., \& Kong, F. (2013). Why do foreign students choose to study in China: An empirical analysis based on survey data from Beijing universities. Higher Education Research (05), 32-38.

Lu, G., \& Tian, M. (2018). An analysis of factors influencing international students' choice of education in China. In F. Dervin, X. Du, \& A. Härkönen (Eds.), International students in China. Cham: Palgrave Studies on Chinese Education in a Global Perspective. Palgrave Macmillan. https://doi.org/10.1007/978-3-31978120-4 2.

Madden-Dent, T., \& Laden, R. M. (2016). Pre-departure cultural preparation for international students: Addressing adjustment needs before study abroad. In K. Bista \& C. Foster (Eds.), Global perspectives and local challenges surrounding international student mobility (pp. 201-222). Hershey, PA: IGI Global. https://doi.org/10.4018/978-1-4666-9746-1.ch011.

Mamiseishvili, K. (2012). International student persistence in U.S. postsecondary institutions. Higher Education, 64(1), 1-17. https://doi.org/10.1007/s10734-011-9477-0.

Mesidor, J., \& Sly, K. (2016). Factors that contribute to the adjustment of international students. Journal of International Students, 6(1), 262-282.

Ministry of Education in China. (2019). Statistics of studying in China in 2018. Retrieved from http://www.moe. gov.cn/jyb xwfb/gzdt gzdt/s5987/201904/t20190412 377692.html

Morrell, D. L., Ravlin, E. C., Ramsey, J. R., \& Ward, A.-K. (2013). Past experience, cultural intelligence, and satisfaction with international business studies. Journal of Teaching in International Business, 24(1), 31-43. https://doi.org/10.1080/08975930.2013.810064.

Mulvey, B. (2019). International higher education and public diplomacy: A case study of Ugandan graduates from Chinese universities. Higher Education Policy. https://doi.org/10.1057/s41307-019-00174-w. 
Nasirudeen, A. M. A., Josephine, K., Adeline, L., Seng, L., \& Ling, H. (2014). Acculturative stress among Asian international students in Singapore. Journal of International Students, 4(4), 363-373.

Nerlich, S., Tan, R., Velliaris, D., Yu, P., \& Lawson, C. (2018). Australian students in China: Making the foreign familiar. In F. Dervin, X. Du, \& A. Härkönen (Eds.), International students in China: Education, student life and intercultural encounters (pp. 121-144). Cham: Springer International Publishing.

Nilsson, P. A. (2015). Life satisfaction among outbound students in northern Sweden. World Journal of Education, 5(4), 87. https://doi.org/10.5430/wje.v5n4p87.

Nye, J. S. (2004). Soft power: The means to success in world politics (1st ed.). New York: Public Affairs.

Park, H.-S., \& Rubin, A. (2012). The mediating role of acculturative stress in the relationship between acculturation level and depression among Korean immigrants in the U.S. International Journal of Intercultural Relations, 36(5), 611-623. https://doi.org/10.1016/j.ijintrel.2012.04.008.

Pattison, S., \& Robson, S. (2013). Internationalization of British iniversities: Learning from the experiences of international counselling students. International Journal for the Advancement of Counselling, 35(3), 188202. https://doi.org/10.1007/s10447-012-9176-2.

Raunic, A., \& Xenos, S. (2008). University counselling service utilisation by local and international students and user characteristics: A review. International Journal for the Advancement of Counselling, 30(4), $262-267$. https://doi.org/10.1007/s10447-008-9062-0.

Saha, N., \& Karpinski, A. C. (2016). The influence of social media on international students' global life satisfaction and academic performance. In K. Bista \& C. Foster (Eds.), Campus support services, programs, and policies for international students (pp. 57-76). Hershey, PA: IGI Global. https://doi.org/10.4018/978-14666-9752-2.ch004.

Salimi, A. (2011). Social-emotional loneliness and life satisfaction. Procedia - Social and Behavioral Sciences, 29(C), 292-295. https://doi.org/10.1016/j.sbspro.2011.11.241.

Sam, D. (2001). Satisfaction with life among international students: An exploratory study. Social Indicators Research, 53(3), 315-337. https://doi.org/10.1023/A:1007108614571.

Smith, R. A., \& Khawaja, N. G. (2011). A review of the acculturation experiences of international students. International Journal of Intercultural Relations, 35(6), 699-713. https://doi.org/10.1016/j. ijintrel.2011.08.004.

Su, J., \& Wang, H. (2015). Research on the status of college students' psychological counseling services. Journal of Chifeng University(Natural Science Edition), 31(12), 77-19.

Sun, L., Feng, J., Lin, L., \& Huang, X. (2009). A survey of acculturation of foreign students in China and some suggestions. Language Teaching and Linguistic Studies, 1, 41-48.

Sun, M. (2019). Analysis and countermeasures on the demands of developmental psychological counseling in higher colleges. Journal of Hubei Open Vocational College, 32(19), 32-36.

Svergun, I. (2016). The determinants of life satisfaction among Chinese students in Finland and Russia. Retrieved Oct 21, 2019, from https:/pdfs.semanticscholar.org/8f15/070a05c0d22492e0473abeb3292 b3368534e.pdf

Tan, Q. (2013). Several questions about the adaptability of foreign students to China. China Adult Education, 000(001), 90-91.

Taušová, J., Bender, M., Dimitrova, R., \& van de Vijver, F. (2019). The role of perceived cultural distance, personal growth initiative, language proficiencies, and tridimensional acculturation orientations for psychological adjustment among international students. International Journal of Intercultural Relations, 69, 11-23. https://doi.org/10.1016/j.ijintrel.2018.11.004.

Tian, M., \& Lowe, J. (2018). International student recruitment as an exercise in soft power: A case study of undergraduate medical students at a Chinese University. In F. Dervin, X. Du, \& A. Härkönen (Eds.), International students in China: Education, student life and intercultural encounters (pp. 221-248). Cham: Springer International Publishing.

Toner, J. (2019). The role of the university library in supporting international students: A survey of practices across UK universities. Journal of Library Administration, 59(7), 812-829. https://doi.org/10.1080 /01930826.2019.1652045.

Wen, W., Chen, L., Bai, Y., \& Cao, H. (2013). A comparative study of international students' experiences and satisfaction in Beijing. Beijing Social Sciences (2), 63-70. https://doi.org/10.13262/j.bjsshkxy. bjshkx.2013.02.028

Wen, W., Hu, D., \& Hao, J. (2018). International students' experiences in China: Does the planned reverse mobility work? International Journal of Educational Development, 61, 204-212. https://doi.org/10.1016/j. ijedudev.2017.03.004.

Wen, W., \& Hu, D. (2019). The emergence of a regional education hub: Rationales of international students' choice of China as the study destination. Journal of Studies in International Education, 23(3), 303-325. https://doi.org/10.1177/1028315318797154. 
Xu, F., Zhang, X., \& Chen, G. (2016). A research on practices of mental health service for overseas students. Journal of University of Shanghai for Science and Technology, 38(2), 188-192.

Yalçin, I. (2011). Social support and optimism as predictors of life satisfaction of college students. International Journal for the Advancement of Counselling, 33(2), 79-87. https://doi.org/10.1007/s10447-011-9113-9.

Yang, P. (2018). Commentary: International students in China-What we know, what we Don't, and what next. In F. Dervin, X. Du, \& A. Härkönen (Eds.), International students in China: Education, student life and intercultural encounters (pp. 249-255). Cham: Springer International Publishing.

Yang, R. (2014). China's strategy for the internationalization of higher education: An overview. Frontiers of Education in China, 9(2), 151-162. https://doi.org/10.3868/s110-003-014-0014-x.

Yang, R. (2015). China's soft power projection in higher education. International Higher Education(46). https://doi.org/10.6017/ihe.2007.46.7938.

Zheng, J., and Kapoor, D. (2020). State formation and higher education (HE) policy: An analytical review of policy shifts and the internationalization of higher education (IHE) in China between 1949 and 2019. Higher Education. Online first: https://doi.org/10.1007/s10734-020-00517-2.

Zhang, J., \& Goodson, P. (2011). Predictors of international students' psychosocial adjustment to life in the United States: A systematic review. International Journal of Intercultural Relations : IJIR, 35(2), $139-162$. https://doi.org/10.1016/j.ijintrel.2010.11.011.

Zhou, L., Han, Y., \& Li, P. (2018). Home away from home: Extending library services for international students in China's universities. The Journal of Academic Librarianship, 44(1), 52-59. https://doi.org/10.1016/j. acalib.2017.12.002.

Zhang, Y. (2018). Using Bronfenbrenner's ecological approach to understand academic advising with international community college students. Journal of International Students, 8(4), 1764-1782. https://doi. org/10.5281/zenodo. 1468084 .

Publisher's Note Springer Nature remains neutral with regard to jurisdictional claims in published maps and institutional affiliations. 